\title{
ELECTRONIC STRUCTURE OF VALENCE BAND OF FERROELECTRIC SbSI CRYSTALS
}

\author{
V. Lazauskas ${ }^{\text {a }}$, V. Nelkinas ${ }^{\text {a }}$, J. Grigas ${ }^{\text {b }}$, E. Talik ${ }^{\mathrm{c}}$, and V. Gavryushin ${ }^{\mathrm{b}}$ \\ ${ }^{a}$ Institute of Theoretical Physics and Astronomy of Vilnius University, A. Goštauto 12, LT-01108 Vilnius, Lithuania \\ ${ }^{\mathrm{b}}$ Faculty of Physics, Vilnius University, Saulètekio 9, LT-10222 Vilnius, Lithuania \\ E-mail: jonas.grigas@ff.vu.lt \\ ${ }^{\mathrm{c}}$ Institute of Physics, Silesian University, Universitetska 4, 40-007 Katowice, Poland
}

Received 12 January 2006

\begin{abstract}
The form and electronic structure of the valence band (VB) of the ferroelectric SbSI crystal was calculated by solving the Hartree-Fock-Roothaan matrix equation. The diagonal eigenvalue matrix $\varepsilon$ gives the electron state energies. These energies were also studied experimentally by PHI 5700 / 660 Physical Electronics Spectrometer using Al $\mathrm{K}_{\alpha}$ monochromatic radiation $(1486.6 \mathrm{eV})$ as the excitation source. The spectrum of the VB electronic levels was approximated by the Gauss functions. The form of the VB depends on the width of the Gauss function and the number of SbSI molecules, which were taken into account in the model of SbSI crystal. The obtained theoretical density of states and the VB form of SbSI crystal is close to the experimental one.
\end{abstract}

Keywords: SbSI, ferroelectric, XPS

PACS: 77.84.-s, 79.60.-i

\section{Introduction}

Antimony sulfphoiodide, SbSI, is a well-known quasi-one-dimensional ferroelectric semiconductor (with $T_{c} \approx 298 \mathrm{~K}$ ), which exhibits plenty of outstanding strongly coupled semiconductive and ferroelectric properties [1]. X-ray photoelectron spectra (XPS) of the valence band $(\mathrm{VB})$ and of the principal core levels for the SbSI single crystals [2,3] in the temperature range of 215-390 K revealed the electronic structure of the VB and large splitting of core level. This splitting is caused by the different valence states of surface and bulk atoms (different bond orders and charges). The experimental results were confirmed by the theoretical $a b$ initio calculations. Audzijonis et al. [4] performed the same theoretical calculations with the same GAMESS program and the same SbSI model as in [3] and came to similar conclusions, however without citation of [3]. The purpose of this paper is to discuss in greater details the form and electronic structure of the VB in SbSI crystals based on the XPS and on theoretical calculations.

\section{Experimental details}

The SbSI single crystals were grown from a vapour phase. The obtained crystals were in the form of needles or small plates of $7 \times 2 \times 1.5 \mathrm{~mm}^{3}$. The orientation of the ferroelectric [001] axis is along the needle. The XPS of the valence band were measured by PHI 5700/660 Physical Electronics Spectrometer in the temperature range of 215-390 K. The excitation source was $\mathrm{Al} \mathrm{K} \mathrm{K}_{\alpha}$ monochromatic radiation $(1486.6 \mathrm{eV})$. The photoelectron spectra as the functions of kinetic energy were analysed in the energy range of $0-1400 \mathrm{eV}$ by a hemispherical mirror analyzer with the energy resolution of about $0.3 \mathrm{eV}$. The measurements were performed on the (110) and (001) crystal surfaces (view of the sample is given in [3]) both cleaved in vacuum, in the low $10^{-10}$ torr range, to obtain a clean surface. The surface stoichiometry and surface quality of the both (110) and (001) cleavage surfaces were quantified from the overview in spectrum. The only contaminant was found to be carbon. No other spectral features showing non-stoichiometry or impurities have been found. C $1 \mathrm{~s}$ signal (at $284.5 \mathrm{eV}$ ) was used as the energy reference to correct the energy shift due to charging which strongly depends on temperature [3]. 


\section{Ab initio calculation of the energy levels}

The electronic structure of the VB of SbSI was calculated by the method based on solving the HartreeFock-Roothaan (HFR) matrix equations, in the Linear Combinations of Atomic Orbitals (LCAO) approach for the molecular orbitals. According to the Koopmans theorem, the one-electron energies obtained from the canonical HFR equations correspond to the approximate energies of the ionization potential. Koopmans theorem applies if the number of electrons in the system is large. Then adding or removing a single electron from the system will not affect the orbitals of the other electrons and they can be assumed fixed. The molecular orbital (MO) $\varphi_{i}$ can be expanded as a linear combination of atomic orbitals (AOs) $\chi_{\mu}$ :

$$
\varphi_{i}(\vec{r})=\sum_{\mu=1}^{M} C_{i \mu} \chi_{\mu}(\vec{r}),
$$

where $\mu$ is the number of the $\mathrm{AO}$, or the set of quantum numbers $n l m$. The coefficients $C_{i \mu}$ are called MO expansion coefficients. For simplicity, a Gaussian orbital basis set is used. The $\mathbf{C}$ matrix is obtained by solving the Hartree-Fock matrix equation

$$
\mathbf{F C}=\mathbf{S C} \varepsilon,
$$

where $\mathbf{F}$ is the Fock matrix and $\mathbf{S}$ are the overlap integrals.

The method of solving Eq. (2) as well as the binding energy, bond strength, and atomic charge calculation is described in [3]. It is supposed that the electron correlation energy is small. Also, the quantum mechanical calculations do not localize the surface states. XPS is a final state spectroscopy but the results qualitatively can be compared with a ground state calculations data. The calculations were performed using the GAMESS program [5].

\section{The model of SbSI crystal}

For the theoretical $a b$ initio calculation of energy levels the molecular model of the SbSI crystal is needed. The model must be a cluster composed from the even number of molecules. The interaction between the clusters is assumed to be weak.

The crystal structure of SbSI contains double chains $\left[(\mathrm{SbSI})_{\infty}\right]_{2}$ consisting of two chains related by a twofold screw axis and linked together by a short and strong $\mathrm{Sb}-\mathrm{S}$ bonds [1]. Weak van der Waals-type bonds of strength $>3.8 \mathrm{eV}$ bind the double chains. The

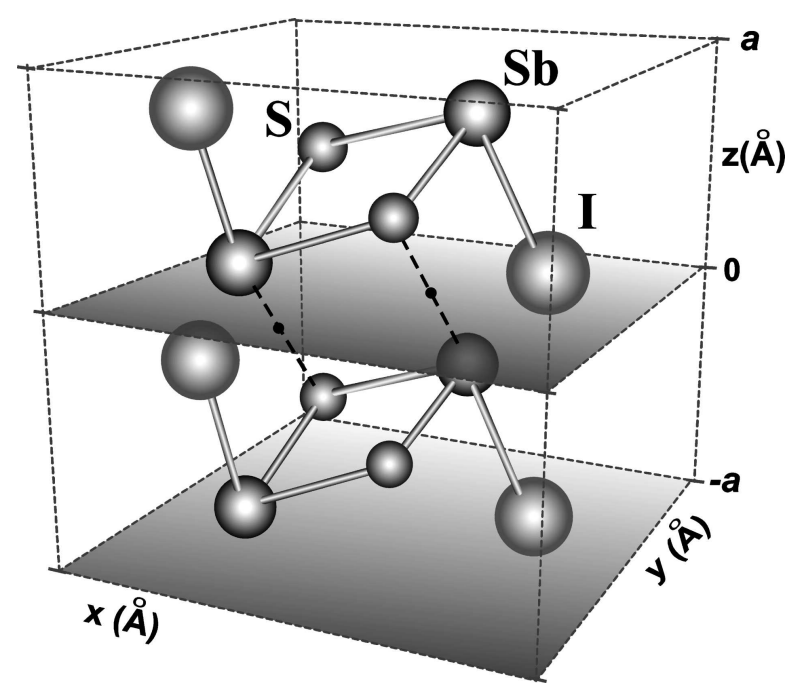

(a)

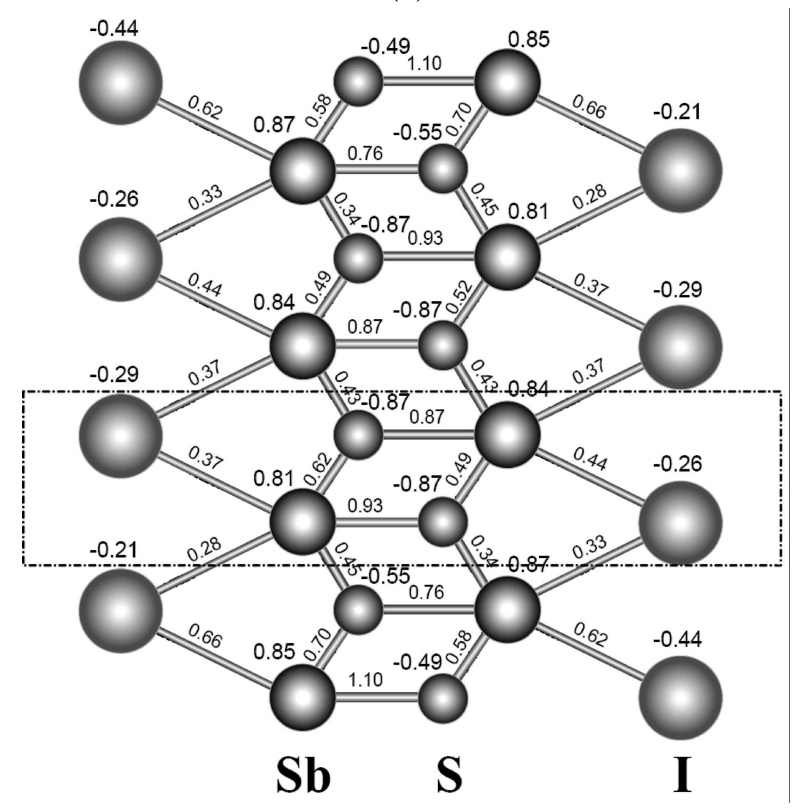

(b)

Fig. 1. (a) Two primitive cells of SbSI crystal. The simplified unit cell is formed by two molecules of SbSI, i.e. by 6 atoms. (b) Molecular chain of SbSI crystal cluster in the $x-y$ plane. Dotted line shows the $x y$ projection of the simplified unit cell. The calculated bond strengths and atom charges are shown in the picture. They are different in different planes from the surface and reveal themselves in the VB electronic structure and core-level splitting.

weakly bonded double chains may be considered as non-interacting and one double chain (Fig. 1) may be taken as a molecular model of the crystal for the binding energies calculation.

The double chain is formed of many simplified unit cells. One such simplified unit cell consists of six atoms. A cluster of two, four, eight, sixteen, and twenty such unit cells has been considered as a molecular model of SbSI crystal for the energy level calcula- 


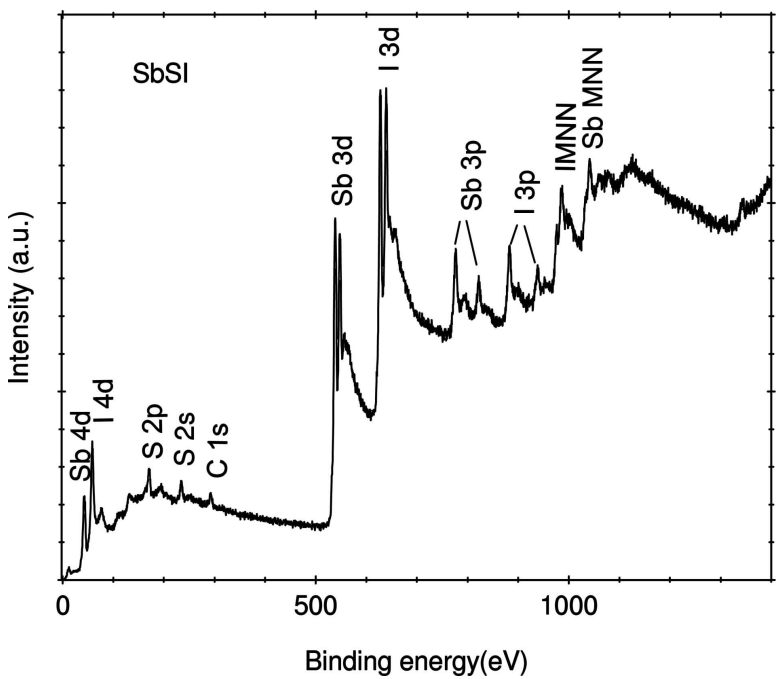

Fig. 2. XPS [3] of SbSI in the energy range of 0 to $1400 \mathrm{eV}$ (the same in paraelectric and ferroelectric phases). The binding energy is negative.

tions. Energy levels slightly change with the increase of the cluster. The model of only two SbSI molecules is sufficient to describe qualitatively the electronic spectrum of the crystal. Due to broken bands on the surface the redistribution of electron density occurs, especially for electronegative $S$ and I atoms. Due to this the band strength of atoms between the first and the second planes increases.

\section{Results and discussion}

Figure 2 shows the overview of the SbSI crystal XPS in the energy range of 0 to $1400 \mathrm{eV}$ below the Fermi level without contamination with any gas and only with a small amount of carbon (C $1 s$ peak at $284.5 \mathrm{eV}$ ). Auger spectra of Sb MNN and of I MNN are also seen in the high energy range. The higher the binding energy, the higher is the XPS background. XPS did not show any traces of impurities, only the carbon was visible after the sample was cleft under high vacuum conditions, in the low $10^{-10}$ torr range. The valence band (VB) lies in the energy range of $0-30 \mathrm{eV}$, i.e. below the $\mathrm{Sb} 4 d$ level energy which dwarfs part of the VB.

Figure 3 shows the experimental VB spectrum in the $\mathrm{P} 2{ }_{1} 2_{1} 2_{1}(295 \mathrm{~K})$ and paraelectric $(350 \mathrm{~K})$ phases. No significant changes occur in this temperature range. In the room-temperature $\mathrm{P} 2{ }_{1} 2_{1} 2_{1}$ phase, the VB is separated by the gap of $1.8 \mathrm{eV}$ from the Fermi level. In the ferroelectric phase, the VB is located at 2.3 to about $20 \mathrm{eV}$ below the $E_{\mathrm{F}}$. The top of the VB is shifted by $\Delta E=0.53 \mathrm{eV}$ with respect to the top of the $\mathrm{VB}$ in the $\mathrm{P} 2{ }_{1} 22_{1}$ phase [3]. In these crystals, the optical band

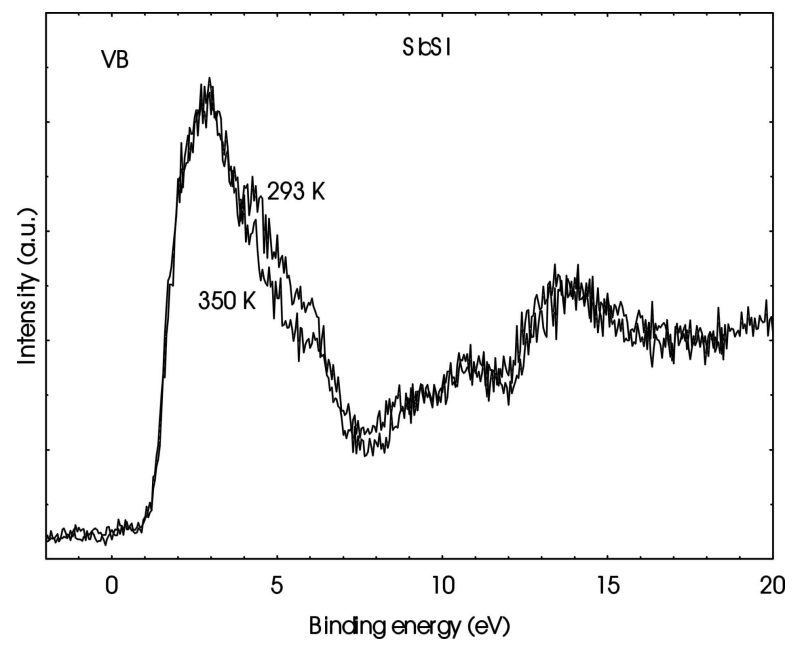

Fig. 3. Experimental VB of SbSI crystal in room-temperature $(295 \mathrm{~K})$ and paraelectric $(350 \mathrm{~K})$ phase. There are no significant changes in the form and electronic structure.

gap obtained from an isoabsorption curve is $1.82 \mathrm{eV}$ at $300 \mathrm{~K}$, while the one in the ferroelectric phase is $1.89 \mathrm{eV}$ at $273 \mathrm{~K}$ and it increases at lower temperatures to $2.2 \mathrm{eV}$ (see [3] and references there). It corresponds to the value obtained from the XPS measurements. The Fermi level is pinned at the bottom of the conduction band. In the ferroelectric phase, the form and structure of the VB does not change significantly [3].

Figure 4 shows theoretically calculated VB form and electronic structure of SbSI crystal. The spectrum is referred to the Fermi level $\left(E_{\mathrm{F}}\right)$. The $E_{\mathrm{F}}$ was defined experimentally with the accuracy of $0.3 \mathrm{eV}$. The intensities of the XPS were described by three ways:

1. By the energy states band $\varepsilon_{i}$ from the characteristic Eq. (2);

2. By the peaks of the density of states (DOS)

$$
D(\varepsilon)=\frac{1}{N_{\mathrm{M}}} \frac{1}{\Delta \varepsilon},
$$

where $N_{\mathrm{M}}$ is the number of molecules in the cluster;

3. By the Gaussian broadening method $[6,7]$ :

$$
D(\varepsilon)=\frac{1}{\sqrt{2 \pi \sigma}} \sum_{i} \exp \left(-\frac{\left(\varepsilon-\varepsilon_{i}\right)^{2}}{2 \sigma^{2}}\right)
$$

where the sum is performed over the states $i, \varepsilon_{i}$ are the corresponding energy levels, and $\sigma$ is the energy broadening parameter.

The Gaussian broadening method is the simplest approach to the Brillouin-zone spectral integrations [7]. The $k$-points are distributed as evenly as possible throughout the Brillouin zone, and the DOS $D(\varepsilon)$ 

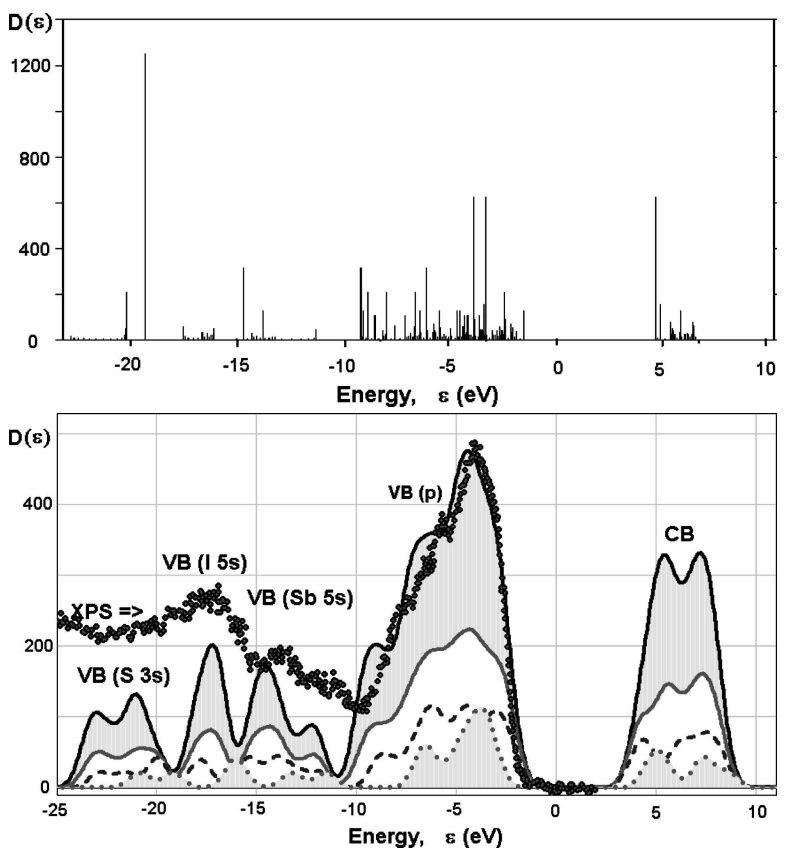

Fig. 4. Electronic structure of SbSI VB. (a) The density of states $D(\varepsilon)$ in Eq. (3) representation for the peaks of the density of states of the valence electrons for 16 molecules SbSI cluster. (b) VB spectra approximation by the Gaussian broadening method (Eq. (4)) for different SbSI molecular clusters from 2 (lowest curve) to 16 (upper curve) and their comparison with experimental XPS. Energy states broadening parameter is $\sigma=0.54 \mathrm{eV}$.

is formed according to Eq. (4). This method is designed for efficient calculation of experimentally observed crystal spectral properties where experimental and lifetime broadenings place a limit on the resolution required.

Further, all experiments have a finite energy resolution and frequently concentrate on the shifts, distortions, and changes in weight in the spectral features. In the used approach (Eq. (4)), the aim was to calculate the DOS only at the high density of $k$-points and then to smear the resulting spectrum to the experimental resolution. However, the application of the Gaussian smearing to the DOS results in good convergence at low $k$-point sampling densities.

Figure 4 gives the comparison of before discussed calculated SbSI VB structure with the experimental XPS spectrum up to $20 \mathrm{eV}$. At higher energies the VB overlaps with $\mathrm{Sb} 4 d$ core level energy (Fig. 2) and is not shown in Fig. 4. Intensity of the bands depends on the density of states. Figure 4(a) shows the representation of $D(\varepsilon)$ for the peaks of the density of states (Eq. (3)). Experimental XPS is the integral picture of all electronic states. In the Fig. 4(b) the approximation of SbSI bands spectra by the Gaussian broadening method (Eq. (4)) for different SbSI molecular clusters (from 2 to 16) and their comparison with experimental XPS is presented.

The calculations give fairly good description of the places and the widths of the VB energy bands. The VB of SbSI is composed of the $s$ and $p$ type bands separated by $2 \mathrm{eV}$ forbidden gap. The $s$ band is formed from the $\mathrm{Sb} 5 s, \mathrm{~S} 3 s$, and I $5 s$ bands of SbSI cluster, separated by narrow gaps. Extending a chain of atoms in cluster, an interval between the I $5 s$ and $\mathrm{Sb} 5 s$ narrows and, at last, disappears. However, the break between the $\mathrm{S}$ $3 s$ and I $5 s$ states remains stable and equal to $1.78 \mathrm{eV}$. Among these bands, formed from the electronegative atoms states, there comes to light the degenerate $S$ level which does not mix up with the levels of other atoms of the cluster, while the $\mathrm{Sb} 5 s$ and I $5 s$ states are disposed to the mixing. The form of the VB can be explained by the analysis of MO population. Knowing the MO coefficients $C_{i \mu}$ (Eq. (1)) one can evaluate the contribution of $\mathrm{A}$ atom electrons for $\varepsilon_{i}$ state:

$$
p_{i A}=\sum_{\mu \in \mathrm{A}} C_{0 i \mu}^{2},
$$

There $\mathbf{C}_{0}=\mathbf{S}^{-1 / 2} \mathbf{C}$ is the matrix of MO coefficients orthogonolized according to Löwdin. The obtained results are shown in Table 1, i.e. the population of the VB states for 4 (SbSI) cluster. All binding energies in Table 1 and Figs. 2-4 are referred to $E_{\mathrm{F}}$. From the Table 1 one can see that the sharp ionisation edge (near to $E_{\mathrm{F}}$ ) of the most intensive $p$ band of the VB is formed by I atom (64\%) of the first plane from the surface perpendicular to the $z$ axis (see Fig. 1(b)) as well as by $\mathrm{S}(21 \%)$ and $\mathrm{Sb}(15 \%)$ electrons. As the Sb $5 p$ contribution is small, the VB edge is sharp. The highest MO of the VB is composed mainly of I $5 p$ of the first surface atomic plane. When the atomic chain is long this level degenerates. The high-energy $p$ band edge of the VB is formed from the S $3 p(56 \%)$ states of the second plane from the surface, as well as by the $\mathrm{Sb} 5 p$ $(30 \%)$ and I $5 p(13 \%)$ states. The lower-energy edge of the $s$ band is formed. by the S (36\%), Sb (52\%), and I (12\%) mixed surface and bulk states. The higherenergy edge of the $s$ band is formed by the S (72\%) states from the second plane from the surface, as well as $\mathrm{Sb}(26 \%)$ and I (2\%) states. There are no states in the VB composed from pure Sb states MOs. Interaction of $\mathrm{Sb}$ atoms with other atoms increases the width of the VB. Sb atoms interact also with the atoms of neighbouring chains (Fig. 1(a)) and also broaden the $p$ band. The conduction band (CB) edge is formed almost $100 \%$ by the $\mathrm{Sb} 5 p$ states from the first surface 
Table 1. Population (in \%) of VB levels in $4(\mathrm{SbSI})$ molecule cluster. VB consists of $s$ and $p$ bands. $\varepsilon_{i}$ is the energy of levels. The last column (D) is the dominant atomic plane from the surface from which photoemission dominates.

\begin{tabular}{|c|c|c|c|c|c|c|}
\hline \multirow[b]{2}{*}{ Band } & \multicolumn{6}{|c|}{$4(\mathrm{SbSI})$ model } \\
\hline & $\begin{array}{l}\text { Atomic } \\
\text { state }\end{array}$ & $\begin{array}{r}-\varepsilon_{i} \\
{[\mathrm{eV}]}\end{array}$ & $\begin{array}{r}\mathrm{Sb} \\
(\%)\end{array}$ & $\begin{array}{r}\mathrm{S} \\
(\%)\end{array}$ & $\begin{array}{r}\text { I } \\
(\%)\end{array}$ & D \\
\hline \multirow[t]{12}{*}{$\operatorname{VB}(s)$} & $\mathrm{S} 3 \mathrm{~s}$ & 22.7 & 26 & 72 & 2 & $\mathrm{~S}_{2}$ \\
\hline & & 21.4 & 20 & 80 & 0 & $\mathrm{~S}_{2}$ \\
\hline & & 19.8 & 12 & 86 & 2 & $\mathrm{~S}_{1}$ \\
\hline & & 19.7 & 14 & 85 & 1 & $\mathrm{~S}_{1}$ \\
\hline & I $5 s$ & 17.8 & 18 & 6 & 76 & $\mathrm{I}_{2}$ \\
\hline & & 17.4 & 6 & 4 & 90 & $\mathrm{I}_{1}$ \\
\hline & & 15.2 & 20 & 8 & 72 & $\mathrm{I}_{1}$ \\
\hline & & 15.2 & 23 & 5 & 72 & $\mathrm{I}_{1}$ \\
\hline & $\mathrm{Sb} 5 s$ & 14 & 58 & 19 & 23 & mixed \\
\hline & & 13.7 & 37 & 23 & 40 & mixed \\
\hline & & 12.8 & 64 & 30 & 6 & mixed \\
\hline & & 11.7 & 52 & 36 & 12 & mixed \\
\hline \multirow[t]{24}{*}{$\operatorname{VB}(p)$} & & 8.8 & 30 & 56 & 14 & $\mathrm{~S}_{2}$ \\
\hline & $\mathrm{S} 3 p$ & 8.2 & 36 & 55 & 9 & $\mathrm{~S}_{2}$ \\
\hline & & 7.8 & 43 & 50 & 7 & bulk \\
\hline & & 7.1 & 33 & 43 & 24 & bulk \\
\hline & & 6.6 & 27 & 48 & 25 & bulk \\
\hline & & 6.5 & 46 & 44 & 10 & bulk \\
\hline & & 6.1 & 31 & 45 & 24 & bulk \\
\hline & & 6.1 & 18 & 60 & 22 & bulk \\
\hline & & 5.9 & 26 & 37 & 37 & bulk \\
\hline & & 5.6 & 28 & 28 & 44 & bulk \\
\hline & I $5 p$ & 5.4 & 32 & 47 & 21 & bulk \\
\hline & & 4.8 & 14 & 66 & 20 & bulk \\
\hline & & 4.6 & 21 & 15 & 64 & bulk \\
\hline & & 4.4 & 24 & 18 & 58 & bulk \\
\hline & & 4.3 & 6 & 50 & 44 & bulk \\
\hline & & 4.2 & 1 & 51 & 48 & bulk \\
\hline & & 3.9 & 2 & 38 & 50 & bulk \\
\hline & & 3.4 & 16 & 32 & 52 & bulk \\
\hline & & 3.2 & 14 & 21 & 55 & bulk \\
\hline & Sb $5 p$ & 2.8 & 2 & 3 & 95 & $\mathrm{I}_{1}$ \\
\hline & & 2.7 & 0 & 0 & 100 & $\mathrm{I}_{1}$ \\
\hline & & 2.6 & 7 & 7 & 86 & $\mathrm{I}_{1}$ \\
\hline & & 2.3 & 14 & 14 & 72 & $\mathrm{I}_{1}$ \\
\hline & & 1.85 & 15 & 21 & 64 & $\mathrm{I}_{1}$ \\
\hline
\end{tabular}

plane. Therefore, the donor level is of Sb $5 p$ states and the acceptor level is of I $5 p$ states.

\section{Conclusions}

The form and electronic structure of the valence band of the ferroelectric SbSI crystal was studied experimentally and calculated by solving the HartreeFock-Roothaan matrix equation. The VB of SbSI is composed of the $s$ and $p$ bands. The $s$ band is formed from the $\mathrm{Sb} 5 s, \mathrm{~S} 3 s$, and I $5 s$ states. The $p$ band is formed thoroughly from $\mathrm{S} 3 p$, Sb $5 p$, and I $5 p$ states. The form of the VB depends on the population of energy levels of surface and bulk atoms. Conduction band edge is formed almost $100 \%$ by the $\mathrm{Sb} 5 p$ surface states.

The form of the VB is well approximated by the Gaussian smearing with $\sigma=0.1 \Delta E$, and that is nearly in accordance with the spectral resolution of the used $\mathrm{X}$-ray photoelectron spectrometer. The VB of SbSI crystal is described well enough already by the model of the two SbSI molecules cluster. The obtained theoretical density of states and the VB form of SbSI crystal is close to the experimental.

\section{References}

[1] J. Grigas, Microwave Dielectric Spectroscopy of Ferroelectrics and Related Materials (Gordon \& Breach Science Publ., OPA, Amsterdam, 1996).

[2] J. Grigas, E. Talik, and V. Lazauskas, Splitting of the XPS in ferroelectric SbSI crystals, Ferroelectrics 284, 147 (2003).

[3] J. Grigas, E. Talik, and V. Lazauskas, X-ray photoelectron spectroscopy of ferroelectric semiconductor SbSI crystals, Lithuanian J. Phys. 44, 427 (2004).

[4] A. Audzijonis, G. Gaigalas, L. Zigas, A. Pauliukas, R. Zaltauskas, A. Cerskus, and J. Narusis, Central Eur. J. Phys. 3, 382 (2005).

[5] M.W. Schmidt, K.K. Baldrige, J.A. Boatz, S.T. Elbert, M.S. Gordon, J.H. Jensen, S. Koseki, N. Matsunaga, K.A. Nguyen, S. Su, T.L. Windus, M. Dupuis, and J.A. Montgomery, General atomic and molecular electronic structure system, J. Comput. Chem. 14, 1347 (1993).

[6] C.J. Pickard and M.C. Payne. Extrapolative approaches to Brillouin-zone integration. Phys. Rev. B 59, 4685 (1999).

[7] R. Hoy and B. Lukiyanets, Density of electron states in compounds $\mathrm{A}^{I} \mathrm{~B}^{I I I} \mathrm{C}_{2}^{I}$, J. Phys. Studies 4, 43 (2000). 


\title{
FEROELEKTRINIU SbSI KRISTALŲ VALENTINĖS JUOSTOS ELEKTRONINĖ SANDARA
}

\author{
V. Lazauskas ${ }^{\text {a }}$, V. Nelkinas ${ }^{\text {a }}$, J. Grigas ${ }^{\text {b }}$, E. Talik ${ }^{\text {c }}$, V. Gavryushin ${ }^{b}$

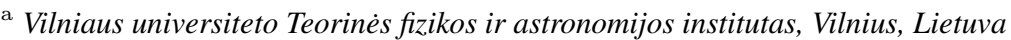 \\ ${ }^{\mathrm{b}}$ Vilniaus universitetas, Vilnius, Lietuva \\ ${ }^{\mathrm{c}}$ Silezijos universiteto Fizikos institutas, Katovicai, Lenkija
}

\section{Santrauka}

Pateikti feroelektrinių SbSI kristalų valentinès juostos (VJ) formos ir elektroninès sandaros skaičiavimai Hartrio-Foko-Rothano (Hartree-Fock-Roothaan) metodu. Gautos energijos palygintos su eksperimentiškai išmatuotomis PHI 5700/660 Physical Electronics spektrometru. Fotoelektronų sužadinimo šaltinis buvo $\mathrm{Al}$ $\mathrm{K}_{\alpha}$ 1486,6 eV monochromatinè spinduliuotė. VJ elektronų lygmenu spektrai aproksimuoti Gauso funkcija. VJ forma priklauso nuo Gauso funkcijos pločio, bet nepriklauso nuo SbSI molekuliu skaičiaus, kvazivienmačiame SbSI kristalo modelyje. VJ sudaryta iš $s$ ir $p$ juostų, kurios savo ruožtu sudarytos iš atitinkamai $\mathrm{Sb} 5 s$, $\mathrm{S} 3 s$ ir I $5 s$ ir Sb $5 p, \mathrm{~S} 3 p$ ir I $5 p$ juostų. Parodyta, kokiu atomu paviršiniai ir tūriniai sluoksniai lemia VJ formą. Laidumo juostą lemia Sb $5 p$ būsenos. Apskaičiuoti paviršiaus ir tūrio atomų elektros krūviai ir ryšiu stipriai. Apskaičiuotas būsenų tankis ir VJ forma gerai sutampa su eksperimentiškai išmatuotais. 